\title{
Prevalence of Hepatitis B and C in Male Prisoners in Iranian Prisons
}

\author{
Ramin Alasvand', Fatemeh Azimian², Seyed-Mostafa Hosseini-Zijoud ${ }^{3}$, Farideh Asadi Dashbolagh4, Mohammad Parsa- \\ Mahjoob5 ${ }^{5}$ Mahmoud Nabavi6,* \\ ${ }^{1}$ Deputy Director of Prisons' Organization Health Center, Tehran, Iran \\ ${ }^{2}$ Officer of Viral Hepatitis Control Unit Iranian CDC, Tehran, Iran \\ ${ }^{3}$ Social Development and Health Promotion Research Center, Kermanshah University of Medical Sciences, Kermanshah, Iran \\ ${ }^{4}$ Heath Center West Branch, Iran University of Medical Sciences, Tehran, Iran \\ ${ }^{5}$ Cardiovascular Research Center, Faculty of Medicine, Shahid Beheshti University of Medical Sciences, Tehran, Iran \\ ${ }^{6}$ Department of Infectious Diseases and Tropical Medicine, Shahid Beheshti University of Medical Sciences, Tehran, Iran
}

*Corresponding Author: Mahmood Nabavi, Assistant Professor of Infectious Diseases and Tropical Medicine, Department of Infectious Diseases and Tropical Medicine Shahid Beheshti University of Medical Sciences, Tehran, Iran. Email: mahmoodnabavi53@yahoo.com

\begin{abstract}
Introduction: Prison, as the most important place for the transmission of infectious diseases, has particular importance, and prison populations are at high risk for infectious diseases like Hepatitis B \& C. This study aimed to determine the prevalence of Hepatitis B \& C among male inmates in six prisons of different provinces in Iran in 2012.

Methods: In this cross-sectional study, 2120 male prisoners from six prisons of Tehran ( $\mathrm{n}=408$ ), Kermanshah ( $\mathrm{n}=400)$, Khorasan Razavi ( $\mathrm{n}=400)$, Kerman $(n=312)$, Isfahan $(n=300)$ and Fars $(n=300)$ were examined. Blood samples were tested for Hepatitis B surface antigen $($ HBsAg) and antibodies to HCV (anti-HCV) by ELISA.

Results: The mean age of the prisoners was $37 \pm 13$ years with a range of $25-59$ years. In total, $73(3.4 \%)$ prisoners were anti-HBc positive and 273 $(12.9 \%)$ prisoners were anti-HCV positive. The lowest prevalence of Hepatitis B and C was observed in Kerman (respectively, 2.52\% and 3.2\%) and the highest prevalence was seen in Isfahan (respectively, 6.3\% and 33.6\%).

Conclusions: We found that the prevalence of Hepatitis B and C among prisoners is considerable. Nevertheless, prisoners routinely are not evaluated and screened for these infections. It is recommended that those who are responsible should apply some policy for reducing and preventing such transmissions in prisons.
\end{abstract}

Keywords: Prison, Prevalence, Hepatitis B, Hepatitis C, Iran

Article History: Received: 10 Jul. 2015; Accepted: 10 Sep. 2015; Online Published: 26 Nov. 2015

Cite this article as: Alasvand R, Azimian F, Hosseini-Zijoud SM, Asadi Dashbolagh F, Parsa-Mahjoob M, Nabavi M. Prevalence of hepatitis B and C in male prisoners in Iranian prisons. Int J Travel Med Glob Health. 2015;3(4):183-6

\section{Introduction}

Viral Hepatitis is one of the top five infectious causes of premature deaths in the world, and every year at least one million people in the world die because of viral Hepatitis. Some investigations have identified these viruses as a cause of death related chronic liver diseases $[1,2]$.

Prison has an important role in the transmission of infectious diseases, placing prison populations at risk of acquiring diseases such as Hepatitis B and C. People in prisons held for a long time in a closed environment and with the conditions such as overcrowding, poor nutrition, lack of medical care, and sexual contact with the same sex are susceptible to various infectious diseases. After release, they disperse in society and spread the disease [3].

Most prisoners have low social status, drug abuse, and risky sexual behaviors that are predictors of Hepatitis outbreak in these people. Also, many of these people are infected in prisons, making prison a source of Hepatitis [4].

According to the latest global statistics, in 2013, more than 10 million people were prisoners in 218 countries, including 217,000 in Iran. Iran is ranked eighth worldwide in terms of number of prisoners and is ranked fourth in the number of prisoners per capita.

Currently, prisoners are not routinely screened and evaluated for these infections [5]. According to various studies, serologic evidence of HCV infection have been seen in one out of every three prisoners. In Iran, about 43 percent of prisoners are drug offenders. It is also believed that drug abusers (injectors) are the main group at risk for $\mathrm{HCV}$ infection.
There are approximately 400 million people infected with Hepatitis B throughout the world, of which 2 million annually die as a result of this infection [6]. It was shown that in Iran, imprisonment is the most common risk factor for getting infected with Hepatitis B. This infection in prisons in other countries is highly prevalent as well $[1,7]$.

Studies show that infections such as AIDS, sexually transmitted diseases and Hepatitis in prisons is growing, and a comprehensive program is needed to reduce the risk of transmission of these diseases [5]. In this regard, some countries have taken measures to reduce the risk.

In two prisons in Germany, along with training and raising the level of knowledge of prisoners, sterile injection equipment is provided for them. It was found that by holding out this program, the percentage of using intravenous drug and the use of common syringes decreased and finally the risk of transmitting HIV, Hepatitis B and C has been reduced [8].

In another study that was conducted in 1993 - 2003 on prisoners, several risk factors for the transmission of diseases such as sexually transmitted diseases, Hepatitis, AIDS and tuberculosis were surveyed, and the most important risk factors were sexual risk behaviors and injection drug abuse. In this study, in order to reduce the risk of transmission of these diseases among prisoners, it was proposed that measures such as informing and raising the knowledge level of prisoners, screening, providing sterile condoms and syringes, treatment and vaccination of prisoners can be effective [9].

As mentioned, malnutrition, lack of adequate medical care, 
overcrowding and sexual contact with the same sex are conditions that put prisoners at risk of disease transmission. Recently, the World Health Organization published an important statement about the health of prisoners. This report provides evidence to show that the transmission of infectious diseases in prisons can be controlled with appropriate strategies [10].

Increasing attention to high-risk individuals is a vital necessity, and prisoners are a high-risk group [11]. The aim of this study is to determine the prevalence of serological Hepatitis B and C among prisoners in various prisons in Iran. Considering that $95 \%$ of prisoners in Iran are men, this study was conducted on men.

In particular, according to the national plan, screening the prisoners for the HIV infection is annually done, but no information about the infection of Hepatitis $\mathrm{B}$ and particularly Hepatitis $\mathrm{C}$ is available. The results may provide useful guidance for the competent authorities of the country in need for more precise control of infectious diseases in prisons.

\section{Methods}

This cross-sectional study was done in 2012. The population of this study was the prisoners of 6 central prisons; Isfahan, Fars, Khorasan Razavi, Kerman, Kermanshah and Tehran. 2120 male prisoners were randomly selected from 6 prisons. The approval ethics of the Shahid Beheshti University of Medical Sciences and permission of the judicial authorities and prison officials were received.

To communicate with prisoners, we got help from the health workers at the prison that were able to do this job and who were also trustworthy to the prisoners. After coding the prisoners, blood samples ( $5 \mathrm{ml}$ blood) were collected and samples were immediately transferred to the laboratory or, if necessary, kept at a temperature of $-20{ }^{\circ} \mathrm{C}$ until transferred to the laboratory. All tests were done in the same laboratory by experts from the Ministry of Health in the same condition. Tests were done by ELISA methods and using kits confirmed by Iran reference laboratory (sensitivity and specificity of $100 \%$ ).

If the initial ELISA test became positive on a sample, the same test was repeated and if the second test became positive, it was referred back to prison. Following the same procedure described above, the samples were transported to the laboratory and the Western blot test was performed and the final result was announced.

To describe data, mean, standard deviation, range, frequency and percentage were used.

\section{Results}

In this study, 2120 male prisoners in 6 different prisons (Isfahan, Khorasan, Kermanshah, Shiraz, Tehran, and Kerman) in Iran were studied. The minimum age was 15 years and maximum age was 74 years with the mean age 37 \pm 13 years. In total, $71 \%$ of them were married.

Among the 2,120 prisoners, 73 prisoners (3.4\%) were tested positive in terms of surface antigen of Hepatitis B (HbsAg), and 273 (12.9\%) prisoners were tested positive in terms of antibody against Hepatitis $\mathrm{C}(\mathrm{HCV} \mathrm{Ab})$. It should be noted that in total, one prisoner of Isfahan and three prisoners of Shiraz were simultaneously infected with both Hepatitis.
As Table 1 states, the highest prevalence of Hepatitis B was in prisons in Isfahan, Khorasan Razavi, Kermanshah, Shiraz, Tehran, and Kerman, respectively and the highest prevalence of Hepatitis C was in Isfahan, Fars, Kermanshah, Khorasan Razavi, Kerman and Tehran prisons, respectively.

\section{Discussion}

According to the World Health Organization (WHO), approximately one-third of the world's population are infected with Hepatitis B virus and about 378 million people $-5 \%$ of the world population- are chronic carriers of the Hepatitis B virus.

Iran is in the category of countries with Moderate endemicity of the global pattern of hepatitis because of the vaccination of infants beginning 21 years ago [12].

Statistics from two decades ago show that almost $35 \%$ of the Iranian population was exposed to the HBV virus, and about $3 \%$ of them were chronic carriers. New investigation shows that the prevalence of chronic Hepatitis B carriers is around $1.7 \%$ in Iran $[13,14]$.

Table 1. The prevalence of Hepatitis B and C in various prisons in Iran

\begin{tabular}{lccc}
\hline prison & $\begin{array}{c}\text { Number of } \\
\text { prisoners }\end{array}$ & $\begin{array}{c}\text { Number of } \\
\text { Hepatitis B (\%) }\end{array}$ & $\begin{array}{c}\text { Number of } \\
\text { Hepatitis C (\%) }\end{array}$ \\
\hline Tehran & 408 & $11(2.7 \%)$ & $25(6.1 \%)$ \\
Kermanshah & 400 & $12(3 \%)$ & $53(13.2 \%)$ \\
$\begin{array}{l}\text { Khorasan } \\
\text { Razavi }\end{array}$ & 400 & $14(3.5 \%)$ & $43(10.7 \%)$ \\
Kerman & 312 & $8(2.5 \%)$ & $10(3.2 \%)$ \\
Isfahan & 300 & $19(6.3 \%)$ & $101(33.6 \%)$ \\
Fars & 300 & $9(3 \%)$ & $41(13.6 \%)$ \\
Total & 2120 & $73(3.4 \%)$ & $273(12.9 \%)$ \\
\hline
\end{tabular}

In the present study, which was performed for the first time in several prisons in different provinces of Iran and with the sample size of 2120 prisoners, $3.4 \%$ of prisoners were positive in terms of Hepatitis B surface antigen.

The lowest prevalence of Hepatitis B was observed in Kerman $(2.5 \%)$ and the highest prevalence was observed in Isfahan $(6.3 \%)$.

In previous studies in this setting in Iran, a higher prevalence has been reported. The prevalence of Hepatitis B was reported in Birjand city 5.8\% [15]. In a study on 1431 male prisoners which was done in 4 prisons of 3 central provinces of Iran, the prevalence of Hepatitis B was $3.6 \%$ [16].

The results of this study in Iran, as a study at a national level, in comparison with other countries are somewhat different. In a study conducted in Australia, 3429 male prisoners were examined and the results showed that $2.5 \%$ of them were positive for HbsAg [17], which is lower than what we found in Iran.

On the other hand, in a national study conducted in Ireland, $8.7 \%$ of prisoners have been infected with the Hepatitis B virus, which is more than the percent observed $(3.4 \%)$ in this study in Iran [18]. This prevalence have been reported $6.5 \%$ in Greek prisoners [19] and in a study conducted in 8 prisons in Italy on 973 people, $6.7 \%$ of people were positive for HbsAg [20].

As calculated by the World Health Organization, about 180 million people (3\% of the world's population) are infected with HCV. Two decades ago, Iran was in the category of countries with HCV prevalence of 1-2.5 percent but now is 
below $1 \%$, and EMRO reports Anti HCV prevalence among blood donors in Iran come $0.04 \%$ [21, 22].

In the present study, the rate of Anti HCV prevalence in prisons was $12.9 \%$. The lowest and highest prevalence of Hepatitis C was observed in Kerman (3.2\%) and Isfahan (33.6\%), respectively. In previous similar studies conducted in prisons in Iran, the prevalence of Hepatitis $\mathrm{C}$ was $37.8 \%$ [16], $40 \%$ [23] and 30.8\% [24], all of which are higher compared to the current study.

Reduction of prevalence suggests that prevention programs in recent years have been very effective in reducing the prevalence. These programs include activities such as vaccination against Hepatitis, commissioning and developing harm reduction programs such as substitution therapy with methadone, triangular clinics, training and consulting prisoners, setting up legal meeting rooms, the distribution of condoms, and availability of disposable razor and so on.

However, the prevalence of Hepatitis $\mathrm{C}$ in Iran is higher than the outbreak reported in Mexico (10\%) [25]. However, other studies conducted in different countries in comparison with Iran have reported higher prevalence in prisons, including Australia 39\% [17], Italy (38\%) [20], Greece $80.6 \%$ [19] and Czech Republic $22.4 \%$ [26]. Lower prevalence of Hepatitis in prisons in Iran is perhaps partly because of beliefs, religious beliefs and relative adherence to Islamic commandments in society.

According to the results of this study and the comparison of it with other studies in different countries, it seems that chance of acquiring Hepatitis $B$ and $C$ viruses increases in prison because of the gathering of people with high-risk behaviors and continuation of these behaviors in the closed prison environment.

Today the most common way of virus transmission in most countries of the world (except Iran) is sexual contact [18, 25]. While in Iranian prisons and society using injection drugs is the most common transmission method [24].

Therefore, authorities should design measures to prevent the spread of infection among people imprisoned which particularly important in prisoners who have been imprisoned for drug-related crime. It might be better that at the beginning of the prison period, drug addicted prisoners be identified and separated from other prisoners and that training programs are used effectively to prevent the spread of the infection among prisoners.

Other necessary acts which can be done in order to prevent infections getting spread is a much more effective prevention. However, in some studies the role of training in prison about the side-effects of the drug abuse and risky behaviors associated with it has been shown much effective. In some countries, sterile and clean injection equipment has been provided for prisoners and various efforts have been made to encourage prisoner to not use drugs and even learn how to use the drug in a sterile technique.

A study has been conducted in Switzerland, Germany and Spain has been proposed in this regard. In these studies, in addition to providing sterile syringes for prisoners, necessary trainings have been given to prisoners and it has been observed that the number of intravenous drug users decreased or at least remained stable and the use of common syringes greatly declined. There was no new case of HIV, $\mathrm{HBV}$ or $\mathrm{HCV}$ and researchers concluded that with the implementation of these programs, risky behaviors in prison was reduced and the probability of disease was significantly reduced [27].

Therefore, it is recommended that national authorities investigate these programs and consider how to implement this program in Iran's prisons. This could prevent further increase in patients with $\mathrm{HBV}$ and $\mathrm{HCV}$ in prisons and in the community in future. Given that the prevalence of Hepatitis in prison is more than the society, prison is an important place for training preventions of viral infections and the prevention of the epidemic.

As to the limitations of the present study, it can be pointed out that the main factors associated with infection such as risky and unhealthy behaviors, tattoo, unlawful sexual intercourse, addiction to drugs and alcohol were not recorded.

\section{Conclusions}

According to this study, Hepatitis $\mathrm{B}$ and $\mathrm{C}$ has a high prevalence among prisoners in Iran. Many prisoners infected with Hepatitis B and C, after being released from prison and returned to the family or previous environment, engage in high-risk behaviors and cause the spread of infection. Therefore regular screening of prisoners, health education on personal and social hygiene, immunization against Hepatitis $\mathrm{B}$, treatment of addiction and possibly treatment of Hepatitis $\mathrm{C}$ among prisoners is recommended.

\section{Acknowledgments}

We gratefully thank the authorities and coworkers in the deputy of the ministry of health of Shahid Beheshti University of Medical Sciences and Pastor Institute for conducting the laboratory tests. We would also like to thank the prison authorities of Isfahan, Khorasan Razavi, Kermanshah, Shiraz, Tehran, and Kerman for running this national project. Also thanks to prisoners who participated in this study. Finally we would like to thank Kirk Allen for assisting the revision of the English of the manuscript.

\section{Authors' Contributions}

Study concept and design: RA, MN; acquisition of data: RA, FA, SMHZ, FAD, MPM, MN; analysis and interpretation of data: RA, FA, MPM, MN; drafting of the manuscript: SMHZ, FAD, MPM, MN; critical revision of the manuscript for important intellectual content; statistical analysis: RA, FAD, MPM, MN; administrative, technical, and material supports; study supervision: RA, MN.

\section{Financial Disclosure}

The authors declared no financial disclosure.

\section{Funding/Support}

Not declared

\section{References}

1. Barros LAS, Pessoni GC, Teles SA, Souza SMBd, Matos MAd, Martins RMB, et al. Epidemiology of the viral hepatitis B and C in female prisoners of Metropolitan Regional Prison Complex in the State of Goiás, Central Brazil. Rev Soc Bras Med. Trop. 2013;46 (1):24-9.

2. Harzke AJ, Baillargeon JG, Kelley MF, Diamond PM, Goodman KJ, Paar DP. HCV-related mortality among male prison inmates in Texas, 1994-2003. Ann Epidemiol. 2009;19(8):582-9.

3. Field MG. HIV and AIDS in the FormerSoviet Bloc. N Engl J Med. 2004;351(2):117-20. 
4. Macalino GE, Vlahov D, Dickinson BP, Schwartzapfel B, Rich JD. Community incidence of hepatitis $\mathrm{B}$ and $\mathrm{C}$ among reincarcerated women. Clin Infect Dis. 2005;41(7):998-1002.

5. Fox RK, Currie SL, Evans J, Wright TL, Tobler L, Phelps B, et al. Hepatitis $\mathrm{C}$ virus infection among prisoners in the California state correctional system. Clin Infect Dis. 2005;41(2):177-86.

6. Holsen DS, Harthug S, Myrmel H. Prevalence of antibodies to hepatitis $\mathrm{C}$ virus and associationwith intravenous drug abuse and tattooing in a national prison in Norway. Eur J Clin Microbiol Infect Dis. 1993;12(9):673-6.

7. Azarkar Z, Sharifzadeh G. Evaluation of the Prevalence of Hepatitis B, Hepatitis C, and HIV in Inmates with Drug-Related Convictions in Birjand, Iran in 2008. Hepat Mon. 2010;10(1):26-30.

8. Stark K, Herrmann U, Ehrhardt S, Bienzle U. A syringe exchange programme in prison as prevention strategy against HIV infection and hepatitis $\mathrm{B}$ and $\mathrm{C}$ in Berlin, Germany. Epidemiol Infect. 2006;134(4):814-9.

9. Niveau G. Prevention of infectious disease transmission in correctional settings: a review. Public Health. 2006;120(1):33-41.

10. Prison health: a threat or an opportunity? Lancet. 2005;366(9479):1.

11. Rotily M, Weilandt C, Bird SM, Kall K, Van Haastrecht HJ, Landolo E, et al. Surveillance of HIV infection and related risk behaviour in European prisons A multicentre pilot study. Eur J Public Health. 2001;11(3):243-50.

12. Saffar H, Ajami A, Saffar MJ, Shojaei J, Sotudeh-Anvari M, ShamsEsfandabad K, et al. Prevalence of hepatitis B virus seromarkers in young adults vaccinated at birth; impact on the epidemiology of hepatitis B infection in iran. Hepat Mon. 2014;14(5):e17263.

13. Alavian S-M. Ministry of Health in Iran is serious about controlling hepatitis B. Hepat Mon. 2007;7(1):3-5.

14. Alavian SM, Hajarizadeh B, Ahmadzad-Asl M, Kabir A, BagheriLankarani K. Hepatitis B Virus infection in Iran: A systematic review. Hepat Mon. 2008;8(4):281-94.

15. Ghanbarzadeh N, Nadjafi-Semnani M. A Study of HIV and other sexually transmitted infections among female prisoners in Birjand. J Birjand Univ Med Sci. 2006;13(3):9-15.

16. Javadi A, Pourahmad M, Ataei B. Relationship between duration and prevalence of hepatitis B \& C and HIV in Iranian prisons. J Med
Counc Iran. 2006;4(24):358-64

17. Crofts N, Stewart T, Hearne P, Ping XY, Breshkin AM, Locarnini SA. Spread of bloodborne viruses among Australian prison entrants. BMJ. 1995;310(6975):285-8.

18. Allwright S, Bradley F, Long J, Barry J, Thornton L, Parry JV. Prevalence of antibodies to hepatitis B, hepatitis C, and HIV and risk factors in Irish prisoners: results of a national cross sectional survey. BMJ. 2000;321(7253):78-82.

19. Malliori M, Sypsa V, Psichogiou M, Touloumi G, Skoutelis A, Tassopoulos N, et al. A survey of bloodborne viruses and associated risk behaviours in Greek prisons. Addict. 1998;93(2):243-51.

20. Babudieri S, Longo B, Sarmati L, Starnini G, Dori L, Suligoi B, et al. Correlates of $\mathrm{HIV}, \mathrm{HBV}$, and $\mathrm{HCV}$ infections in a prison inmate population: results from a multicentre study in Italy. J Med Virol. 2005;76(3):311-7.

21. Alavian S-M, Adibi P, Zali M-R. Hepatitis $\mathrm{C}$ virus in Iran: Epidemiology of an emerging infection. Arch Iranian Med. 2005;8(2):84-90.

22. Ghavanini A, Sabri M. Hepatitis B surface antigen and anti-hepatitis $\mathrm{C}$ antibodies among blood donors in the Islamic Republic of Iran. East Mediterr Health J. 1999;6(5-6):1114-6.

23. Malekzadeh R, Khatibian M, Hoori R. Hepatitis in Iran and the World, epidemiology, diagnosis and treatment. J Med Counc Iran. 1997;4(15):183-202.

24. Zakizadeh M, Sadeghian A. Prevalence of HCV infection and related risk factors in drug-addicted prisoners. Armaghane-Danesh. 2002;97:55-64.

25. Alvarado-Esquivel C, Sablon E, Martinez-Garcia S, EstradaMartinez S. Hepatitis virus and HIV infections in inmates of a state correctional facility in Mexico. Epidemiol Infect. 2005;133(4):67985

26. Klusonova H, Stepanova V, Cizek J, Pliskova L. [Viral hepatitis in users of addictive drugs in the Czech Republic]. Epidemiol Mikrobiol Imunol. 2004;53(2):47-54.

27. Dolan K, Rutter S, Wodak AD. Prison-based syringe exchange programmes: a review of international research and development. Addict. 2003;98(2):153-8. 